\title{
РЕШЕНИЕ ПРОБЛЕМЫ ЭКОНОМИЧЕСКОЙ ОЦЕНКИ ЭФФЕКТИВНОСТИ ЭНЕРГОСБЕРЕГАЮЩИХ ТЕХНОЛОГИЙ В МАЛОЭТАЖНОМ СТРОИТЕЛЬСТВЕ
}

\section{SOLVING THE PROBLEM OF ECONOMIC ASSESSMENT OF THE EFFECTIVENESS OF ENERGY-SAVING TECHNOLOGIES IN LOW-RISE CONSTRUCTION}

\section{Z. Kiramov}

Summary: The article proposes the basic principles of solving the problem ofeconomicassessment of the effectiveness of energy-saving technologies in low-rise construction The main content of the study is the analysis of the relationship between the theories and positions of economic scientists, L. Erhard, L. Von Mises, F. Hayek, on the implementation of the social market economy, the relationship between the plan and the market with the problem of assessing the economic efficiency of the use of energy-saving technologies. The article analyzes and describes the theory of "Social market economy" and "Neoliberalism", as the basis of the works of the above-mentioned figures of economic science. Also, in order to identify the success of the application of the theories of L. Erhard, L. Von Mises, F. Hayek to solving the problem of economic assessment of the effectiveness of energy-saving technologies in low-rise construction, the conditions and tactics for assessing energy saving, the main problems of applying the works of scientists were considered, the main principles of policy on implementation energy saving measures.

Keywords: social-market economy, neoliberalism, energy saving, low-rise construction, calculation argument.

\section{Введение}

В настоящее время актуальной стратегией экономики Российской Федерации является становление на путь инновационного, социально-ориентированного развития. По словам Председателя Центрального банка РФ Набиуллиной Э.С. «время, когда конкурентоспособность поддерживалась дешевизной сырья, рабочей силы... уходит в прошлое. Постоянное удорожание энергоносителей ведет к увеличению издержек». Исходя из этого, она делает следующий вывод: «единственный адекватный ответ, который... экономика должна дать на этот вызов, - значительное повышение эффективности, что требует инвестиций и новых технологий» [6, С. 9].

Одним из современных направлений в строительной отрасли экономики является применение энергосберегающих технологий, однако система оценки их эффек-
Кирамов Зуфар Рафисович Аспирант, ФГБОУВО «Тюменский индустриальный университет» zufar.kiramov@gmail.com

Аннотация: В статье предложены основные принципы решения проблемы экономической оценки эффективности энергосберегающих технологий в малоэтажном строительстве. Основное содержание исследования составляет анализ взаимосвязи теорий и позиций деятелей экономической науки, Л. Эрхарда, Л. Фон Мизеса, Ф. Хайека, по проблемам реализации социальной рыночной экономики, соотношения плана и рынка с проблемой оценки экономической эффективности применения энергосберегающих технологий. В статье проанализированы и охарактеризованы теории «Социального рыночного хозяйства» и «Неолиберализма», как основы трудов вышеупомянутых деятелей экономической науки. Так же для выявления успешности применения теорий Л. Эрхарда, Л. Фон Мизеса, Ф. Хайека к решению проблемы экономической оценки эффективности энергосберегающих технологий в малоэтажном строительстве были рассмотрены условия и тактика оценки энергосбережения, основные проблемы применения трудов ученых, определены главные принципы политики по внедрению энергосберегающих мероприятий.

Ключевые слова: социально-рыночное хозяйство, неолиберализм, энергосбережение, малоэтажное строительство, калькуляционный аргумент.

тивности еще требует совершенствования. Важным критерием для определения эффективности применения технологий выступает как получение выгоды частным физическим или юридическим лицом, так и значимость для экономики государства в целом.

В связи с этим целью работы является анализ взаимосвязи теорий и позиций деятелей экономической науки по проблемам реализации социальной рыночной экономики, соотношения плана и рынка с проблемой оценки экономической эффективности применения энергосберегающих технологий. Для достижения поставленной цели необходимо решить следующие задачи:

- рассмотреть теорию «социального рыночного хозяйства» и ее реализацию;

- изучить дискуссии относительно соотношения плана и рынка; 
- рассмотреть понятие и тактику оценки энергосбережения;

- изучить условия, необходимые для расчета экономии энергии;

- проанализировать основные проблемы проведения политики по внедрению энергосберегающих технологий;

- рассмотреть возможность применения теорий деятелей экономической науки для решения проблемы оценки экономической эффективности применения энергосберегающих технологий.

Степень исследованности вышеописанных проблем отражена в трудах Л. Эрхарда, Л. Фон Мизеса, Ф. Хайека и др.

\section{1. Теория «сочиального рыночного хозяйства»} ^. Эрхарда и ее реализачия

В текущих условиях под социальным рыночным хозяйством (социальной рыночной экономикой) понимается экономическая общественная система, обеспечивающая высокую эффективность рыночной экономики и социально-экономический прогресс [10, С. 97]. Ее основными элементами являются:

- экономическая дееспособность;

- социальная справедливость и обеспеченность;

- личная свобода.

Эти идеи лежат в основе политики западногерманского доктора экономических и социальных наук Людвига Эрхарда (1897-1977), теоретика и практика рыночной экономики [6]. Л. Эрхард считал, что «никакая экономическая ситуация не может быть настолько безнадежной, чтобы решительная воля и честный труд всего народа не могли справиться с ней» [15, С. 124]. Такая точка зрения подчеркивает веру в положительный результат усилий, стараний, труда и самоотверженности для экономики.

Л. Эрхард охарактеризовывает позицию социального рыночного хозяйства следующим образом. В основе социального рыночного хозяйства лежат свобода и ответственность индивидуума. Рыночное хозяйство в силу конкуренции, основанной на борьбе за объективные результаты деятельности, исключает любую попытку государства злоупотребить хозяйственной силой как инструментом политической власти. Задачей государственной политики является соединение свободы, порядка, индивидуализма и коллективизма в гармоничное единство с целью достижения «благосостояния для всех» [14]. Цель - обеспечить каждому индивидууму необходимый минимум и создать условия, чтобы любой из них при желании был в состоянии обеспечить себе желанный максимум.
Нет ничего важнее, чем возможность раскрепостить человека, дать простор его энергии, инициативе, обеспечить ему достойное существование, удовлетворить материальные и духовные потребности.

Большое значение Л. Эрхард придает смыслу термина «социальный». Социальность изначально присуща рыночной экономике. Эффективность социальной политики государства не определяется ее масштабами. Правильная социальная политика должна ориентироваться на поддержку позиций каждого отдельно взятого человека: обретая самостоятельность и независимость от опеки государства, гражданин превращается в свободного человека, ответственного за самого себя, свою семью. Наконец, чем богаче общество, тем меньше людей нуждается в социальных благах, предоставляемых государством.

Заслугой Л. Эрхарда является то, что его реформы создали предпосылки для реализации модели социального рыночного хозяйства на практике. Для проведения эффективной экономической политики нужно было, чтобы выполнились следующие важнейшие требования:

- проводимая политика должна быть понятной гражданам;

— политики должны убедить людей в её верности и правильности;

- политика должна быть последовательной;

- политика должна быть открытой и честной;

- политика должна быть правильно выстроена тактически, то есть ориентироваться не только на долгосрочный, конечный результат, но и демонстрировать свою убедительность и эффективность в разумные, с точки зрения ожидания населения, временные сроки.

Применение такой концепции в Германии прошло очень успешно, но государственная бюрократия была сильнее и преувеличила свою роль в хозяйственном развитии. В результате «порядка» становилось всё больше и больше, а «свободы» всё меньше и меньше. Появилась опасность превращения рыночной свободы в свободу, направляемую и контролируемую государством. Политика стала представлять собой одновременно и либерализм, и плановую экономику. Однако при воплощении социального рыночного хозяйства важно, чтобы свобода регулировалась снизу, а не сверху, чтобы между свободой, самостоятельностью и ответственностью существовала взаимосвязь. Если этот баланс нарушается, то нарастает зависимость людей от государства, а свободные граждане превращаются его подданных. Социальные блага должны быть заработаны самими трудящимися, а не даны государством. 


\section{2. Аискуссии в экономической науке относительно соотношения плана и рынка ( ^. Фон Мизес, Ф. Хайек)}

\section{1. Теория неолиберализма}

В качестве базы концепции германского социального рыночного хозяйства выступает теория ордолиберализма. При этом ордолиберализм является немецким вариантом теории неолиберализма [7, С. 90], основанной на теории классического либерализма.

Неолиберализм понимается как вариация классических взглядов либералов, выражающая неприятие тоталитарных общественных систем и допускающая присутствие элементов государственного регулирования в экономике. Неолиберальные экономические и социальные проекты в обязательном порядке включают узаконенные требования защиты конкуренции от монопольной власти. Они различаются разработкой направлений, позволяющих решить проблему объединения свободы и поддержки социально незащищенных слоев населения. Спектр неолиберализма представлен в Таблице 1 [7, C. 43].

2.2. Л. Фон Мизес и Ф. Хайек как представители неолиберализма

Лондонская школа неолиберализма считается классической. Ее основателем является Людвиг Фон Мизес (1881-1973), который рассматривал проблемы экономического равновесия и вопросы конкуренции в изменяющихся экономических условиях. Он утверждал, что централизованное регулирование цен делает невозможным достижение экономического равновесия в условиях плановой экономики [4, С. 77], потому что вне свободно меняющихся цен централизованная экономика не предусматривает наличия инструментов эффективного планирования. Л. Фон Мизеса называл системы плановой государственной экономики «планируемым хаосом».

Спектр неолиберализма подразделяется на: [7, С. 43].

1. Неолиберализм в узком смысле слова. Фридрих А. Хайек: «Обновить классический либерализм!»;

2. Ревизия неолиберализма;

2.1 Либеральный интервенционизм;

2.1.1 Общественно-политический неолиберализм. Вильгельм Репке: «Укреплять силы общественной интеграции!»;

2.1.2 Неолиберализм в рыночной политике. Александр Рюстов: «Поддерживать структурные изменения путем содействия приспособлению хозяйствующих субъектов!»;

2.1.3 Социальный неолиберализм. Альфред Мюллер-Армак: «Поставить рыночное хозяйство на службу социальному!»;

2.2 Ордолиберализм. Вальтер Ойкен, Франц Бём: «Создать и поддерживать конкурентный порядок!»;

3. Социальное рыночное хозяйство. Людвиг Эрхард: «Систематическая экономическая политика, содействующая свободе!».

Отцом лондонской школы неолиберализма считается ее представитель - Фридрих Август фон Хайек (1899-1992), ученик Л. Фон Мизеса. С его точки зрения рыночная система обеспечивает синтез предельно конкретного знания с предельно абстрактным. Под первым понимается индивидуальное знание специфических условий времени, места и образа действий [13, С. 199]. Умение пользоваться этими условиями в конечном итоге обеспечивает индивидуальные преимущества. Свободный рынок создает предпосылки для использования этого знания, наделяя правом распоряжаться им обладателей этого знания.

Конкуренция в трудах Ф. Хайека - динамический процесс, а понятие «совершенная конкуренция» изначально исключает возможную конкурентную деятельность [14]. Конкуренция трактуется как метод порождения новых знаний. Этому способствует открытие новых потребностей, неизвестных до этого, и соответственно новых способов их удовлетворения. Кроме этого, экономические деятели узнают о своих способностях по сравнению с другими.

В итоге искусственное ограничение конкуренции сокращает объем знаний, доступных обществу. По мнению Ф. Хайека, наступление государства можно остановить, если либералы будут самостоятельно разрабатывать и реализовывать меры по преодолению трудностей, с которыми сталкивается современный мир. «Конкуренция есть процесс формирования мнения: путем распространения информации она создает единство и согласованность экономической системы» [12, С 106]. Государственное вмешательство препятствует распространению информации, поэтому его функции должны быть строго ограничены [11, С 132].

Одним из видов критики плановой экономики, предложенным Л. Фон Мизесом в 1920 году и подробнее исследованным Ф. Хайеком является калькуляционный аргумент. Он относится к проблеме рационального распределения ресурсов в экономике. В рыночной экономике эта проблема решается при помощи механизма спроса и предложения, при котором люди имеют возможность решать, как именно будут распределяться товары или услуги при помощи своей готовности отдавать деньги за них. Цена товара содержит информацию о балансе спроса и предложения, необходимую для корректирования возникающего избытка и дефицита. Л. 
Фон Мизес и Ф. Хайек считают такой механизм регулирования единственно возможным, потому что плановая экономика не имеет возможности рационального распределения ресурсов из-за отсутствия информации, получаемой при помощи рыночных цен.

Л. Фон Мизес считал, что «...рациональная экономическая активность невозможна в социалистической экономике», дефицит является неотъемлемой частью социалистической экономики, потому что способа получить рациональные цены не существует, если все средства принадлежат государству, так как цены на них просто характеризуют возможность внутренней передачи этих средств, а не результат обмена [12, С 137]. Как следствие, оценка средств становится невозможной. Это означает, что планирующий орган будет лишен возможности рационального распределения ресурсов.

\section{3. Применение теорий $\wedge$. ЭрхарАа, \\ ^. Фон Мизеса и Ф. Хайека к решению проблемы экономической ошенки эффективности энергосберегаюших технологий в малоэтажном строительстве}

\section{1. Понятие энергосбережения}

Для того, чтобы оценить возможность применения теорий Л. Эрхарда, Л. Фон Мизеса и Ф. Хайека к решению проблемы оценки эффективности энергосберегающих технологий, в первую очередь рассмотрим понятие энергосбережения и его актуальность.

Энергосбережение - это комплекс мер по реализации организационных, правовых, технических, экономических и иных мер, направленных на эффективное (рациональное) использование топливно-энергетических ресурсов и на вовлечение в хозяйственный оборот возобновляемых источников энергии [2, С. 2].

Энергосбережение является одной из важных задач XXI века, так как потребление тепловой и электрической энергии необходимое условие жизнедеятельности человека и создания благоприятных условий его быта [5, С. 15].

Повышение конкурентоспособности, финансовой устойчивости экономической и экологической безопасности, а также роста уровня качества жизни населения невозможно без потенциала энергии и повышения энергетической эффективности на основе модернизации технологического развития и перехода к рациональному и экологически ответственному использованию энергетических ресурсов [3, С. 85]. От результатов решения этой проблемы зависит место общества среди развитых в экономическом отношении стран.
В настоящее время огромное количество тепла, воды и электричества используется неэффективно.

Задачу снижения энергоемкости экономики ставит руководство государства, ученые и эксперты предлагают варианты ее решения. Безусловно, широкое внедрение энергоэффективных технологий позволит сберечь киловатты электричества, миллионы кубометров газа, сократить вредные выбросы в атмосферу, и не переплачивать за энергию, потраченную впустую.

Для начала необходимо менять отношение общества к использованию природных ресурсов и энергии. Но ощутимого результата можно добиться только при внедрении системного подхода к энергосбережению, а также к оценке экономической эффективности применения энергосберегающих технологий. Большую роль сейчас играет вопрос о том, какую пользу энергосбережение может принести как для экономики всей страны, так и для бюджета каждого конкретного предприятия или домашнего хозяйства. Комплексное внедрение современных энергосберегающих технологий в малоэтажное строительство позволит эффективно использовать энергию и сократить срок окупаемости данных технологий.

Причинами, по которым вопросы энергосбережения и энергоэффективности становятся более актуальными, являются:

- дефицит и постоянное уменьшение природных ресурсов;

- постепенное увеличение потребления энергоресурсов;

— рост цен на энергоресурсы.

Самым большим препятствием к широкому внедрению энергосберегающих технологий является невозможность оценки материальной выгоды. Чем большие вложения требует проект, тем большую отдачу он должен обеспечить. По этой причине были разработаны методики расчета экономического эффекта от внедрения современных энергосберегающих технологий.

\section{2. Тактика оценки энергосбережения}

Организация по оценке эффективности (EVO) выпустила справочник IMPVP - международный протокол по контролю и верификации экономии финансовых средств, который описывает тактику измерения, расчета и анализа сбережения материальных средств [16]. Первый том справочника IPMVP выпущен для оценки эффективности энергосберегающих мероприятий. Он предлагает методы с различными уровнями стоимости и точности для расчета экономического эффекта при внедрении энергосберегающих технологий. 
Одним из факторов того, что Л. Эрхард добился успешного проведения эффективной экономической политики, стала ее тактическая правильность и ориентированность на разумные сроки. Поэтому перед внедрением энергоэффективной технологии, необходимо определить временной (исходный) интервал.

Определение исходного интервала производится в следующем порядке: с течением времени производятся измерения потребляемой энергии, а после внедрения энергоэффективной технологии производится расчет возможного энергопотребления предприятия, если бы не произошло модернизации. Для этого используются данные, полученные в исходном периоде времени. Разница между реальным и расчетным энергопотреблением в последующий временной период (отчетный), который равен исходному периоду, составляет экономию энергии от внедрения новой технологии.

\section{Для расчета экономии используется формула 1:}

Экономия = Потребление в базовый период - потребление в отчетный период \pm поправка на изменение условий (1)

3.3. Условия, необходимые для расчета экономии энергии

Согласно методике IPMVP для проведения расчета энергоэффективности должны быть выполнены следующие условия:

- точность: данные измерений должны быть максимально точными;

- законченность: отчет об энергосбережении должен включать в себя выводы о выгодах от модернизации;

- консервативность: если какие-либо параметры сложно измерить или оценить, то необходимо использовать наиболее невыгодные значения;

- единообразность: отчет по энергосбережению должен быть единообразным;

- существенность: при определении экономии необходимо измерять наиболее существенные параметры, а менее важные параметры могут быть оценены с допущениями;

- прозрачность: все произведенные измерения и расчеты должны быть подробно описаны.

Вышеизложенные условия соответствуют принципу Л. Эрхарда о верности и правильности проведения эффективной экономической политики.

3.4. Основные проблемы проведения политики по внедрению энергосберегающих технологий и способы их решения
Реализация политики по повышению энергоэффективности требует модернизации экономики, внедрения нового технологического уклада, придания социальноэкономическому развитию инновационной направленности, активизации соответствующих технологических и управленческих механизмов во всех секторах экономики и социальной сферы, системного подхода и скоординированных мер [9]. Основными проблемами проведения политики повышения энергоэффективности являются:

- отсутствие системности проводимой политики;

- отсутствие верной информации о потреблении энергии;

- отсутствие мотивации к энергосбережению, неуверенность в необходимости применения новых технологий;

- высокая, экономически необоснованная стоимость энергосберегающих технологий.

Поэтому главными принципами политики по внедрению энергосберегающих мероприятий должны стать системность и последовательность принимаемых мер, их понятность, убедительность и честность. Эти принципы лежат и в основе проведения эффективной экономической политики по Л. Эрхарду.

В основном энергоносители не являются обычными рыночными товарами, их рынок сильно монополизирован. Их внутренние цены оказывают значительное влияние и на производителей, и на потребителей, и на темпы экономического роста. Поэтому, если рассматривать позиции Л. Фон Мизеса и Ф. Хайека насчет конкуренции и плановой экономики применительно к проблеме применения энергосберегающих технологий, то политику воздействия на цены энергоресурсов и на методы их регулирования напротив должно определять государство [8, C. 31].

Основные операции по подготовке к осуществлению применения энергосберегающих технологий и выполнению принятых плановых решений не могут быть правильно осуществлены при существующих моделях конкурентного рынка [1, С 14]. Это невозможно из-за технологического несоответствия цепочке «производство передача - распределение - потребление энергоресурсов», поэтому она должна быть исключена из рыночного пространства. У такой системы собственником может являться исключительно государство.

Таким образом, системные проблемы эффективного использования энергоресурсов не могут быть разрешены в условиях либеральной рыночной философии, которую пропагандировали Л. Фон Мизес и Ф. Хайек. 


\section{Зак^ючение}

Таким образом, в ходе работы решены следующие задачи:

- рассмотрена теория «социального рыночного хозяйства» и ее реализация;

- изучены дискуссии относительно соотношения плана и рынка;

- рассмотрены понятие и тактика оценки энергосбережения;

- изучены условия, необходимые для расчета экономии энергии;

- проанализированы основные проблемы проведения политики по внедрению энергосберегающих технологий;

- рассмотрена возможность применения теорий деятелей экономической науки для решения проблемы оценки экономической эффективности применения энергосберегающих технологий.

Подводя итоги, можно сказать, что проблема проведения экономических преобразований всегда была в центре экономических исследований как в России, так и в других странах мира, в том числе в Германии. Изменялись лишь подходы к ней в зависимости от сложившейся в странах социально-политической обстановки. Вопрос о соотношении плановых и рыночных методов регулирования экономики до сих пор остается открытым.

В России существуют большие возможности для повышения эффективности использования энергии как в сфере производства и передачи, так и в сфере ее потребления. Однако нормальное функционирование российского общества в настоящее время возможно лишь при условии оптимального сочетания плановых и рыночных методов хозяйствования.

\section{ЛИТЕРАТУРА}

1. Беляев Л.С. Недостатки конкурентного рынка электроэнергии и целесообразность корректировки концепции реформирования электроэнергетики России. // Энергетик. - 2006. - №5. - С. 13-17.

2. Беляев, В.С. Проектирование энергоэкономичных и энергоактивных гражданских зданий - М.: Высшая школа, 2013. - 254c.

3. Богословский, В.Н., Эминов, В.С. Особенности теплообмена и оценка комфортности условий в помещении при совмещении отопления и охлаждения // ABOK. 2012. № 6. - C. 85-88

4. Костюк В.Н. История экономических учений. - М.: Центр, 1997. - 139с.

5. Матросов, Ю., Бутовский, И., Гольдштейн, Д. Новая концепция нормирования теплозащиты зданий. Энергетическая эффективность // Бюллетень ЦЭНЭФ. - М.: 2014. - С. 15-18.

6. Набиуллина Э.С. Приоритеты деятельности на 2008г. и среднесрочную перспективу // Экономист. — 2008. — №4. — С. 9.

7. Нуреев Р.М., Латов Ю.В., Сидорина Т.Ю. Социальное рыночное хозяйство: концепция, практический опыт и перспективы применения в России. Москва: ГУ-ВШЭ, 207. — 325 с.

8. 0 регулировании цен на энергоресурсы // Научная электронная библиотека «Киберленинка» URL: https://cyberleninka.ru/article/n/0-regulirovanii-tsen-naenergoresursy/viewer (дата обращения: 15.11.2020).

9. Реализация политики повышения энергоэффективности в России. Позиция регионов // Энергосовет URL: http://www.energosovet.ru/bul_stat. php?idd=311 (дата обращения: 07.11.2020).

10. Социальное рыночное хозяйство: Словарь терминов / Л. Л. Васина, Рос. независимый ин-т соц. и нац. проблем. — М. : ИНФРА-М, 1997. - 188с.

11. Хайек Ф.А. Пагубная самонадеянность: Ошибки социализма. — М.: Новости, 1992. — 306с.

12. Хайек Ф.А. Смысл конкуренции / Индивидуализм и экономический порядок. - М.: Изограф, 2001. — 256с.

13. Экономическая теория в ретроперспективе (история экономических учений): учебное пособие / И.А. Ашмаров. — Москва; Берлин: Директ-Медиа, 2019. - 380c.

14. Эрхард Л. Благосостояние для всех: Транс. с ним. - М.: Старт-пресс, 1991. — 261с.

15. Эрхард Л. Полвека размышлений. Речи и статьи /Л. Эрхард. — Москва: Руссико, 1993. — 608с.

16. International Performance Measurement and Verification Protocol (IPMVP) // Efficiency Valuation Organization URL: https://evo-world.org/en/products-servicesmainmenu-en/protocols/ipmvp (дата обращения: 28.11.2020). 